\title{
Guidelines to shape clinical practice. The role of medical societies: the Dutch experience in comparison with recent developments in the American approach
}

\author{
A.F. Casparie \\ Department of Health Policy and Management, Erasmus University Rotterdam \\ and the National Organization for Quality Assurance in Hospitals, Utrecht, \\ The Netherlands
}

Accepted 28 April 1991

\section{Summary}

In the last fow years there has been a growing interest in the development of guidelines for care. The most important aim of these guidelines is to improve the quality of care by changing the daily practice of physicians in the desired direction. Therefore besides the scientific basis of guidelines, emphasis should be placed on the implementation of guidelines. Experiences in the Notherlands, where medical societies contribute significantly to the procedure of consensus guidelines deveropment, are described in comparison with now ideas in the U.S.A. regarding criteria setting. Involvement of physician organisations to the development procedure is a necessary requirement for guidelines to shape clinical practice. Furthermore, some interventions used in The Netherlands for improving implementation of guidelines in daily practice are mentioned.

Guidelines for care; Quality assurance; Cuality improvement; Implementation of guidelines

Address for correspondence: Professor A.F. Casparie, M.D., Ph.D., Department of Health Policy and Management, Erasmus University Rotterdam, P.O. Box 1738, 3000 DR Rotterdam, The Netherlands. 


\section{Introduction}

One of the most important elements in the procedure of quality improvement and quality assurance is guidelines for care, since they have to indicate how daily medical practice should be carried out. Furthermore, these guidelines can be the basis of criteria and standards used to assess the quality of care.

In the last few years, especially in the U.S.A., there has been growing interest in the establishment of guidelines. Guidelines is the generic name for standards, parameters, preferred practice patterns and so on, all designed to guide clinical decision-making. Reasons for developing guidelines are rising health care costs, variations in practice performance by physicians and reports of inappropriate care [1]. Other goals sometimes mentioned are resolution of ethical or legal questions, to help manage malpractice risks, for reimbursement and for protecting the territory of a particular specialty $[2,3]$. In the U.S.A. different organisations are involved in developing guidelines, such as medical societies and insurance companies, so it is not surprising that guidelines contain conflicting recommendations [4].

However, the most important aim of guidelines is to improve the quality of care. Practical guidelines are not a new phenomena in medical care and some of them have had an impressive influcnce, such as washing hands between deliveries [5]. The systematic approach is new, as is the use of various methods for developing guidelines and their explicit character. To influence the daily practice of care these guidelines must fulfill, however, some prerequisites. It must be realised that a gap in a physician's knowledge is not the reason that his practice is not run as it should be. Instead, there are several other reasons, such as defensive medicine, financial incentives, traditional practice habits or routine actions and pressure from the patient which hamper changes in clinical behaviour and which are the cause of a low compliance with even scientifically sound guidelines. For example, scientifically based guidelines regarding the use of cesarean sections do no guarantee good practice in agreement with the recommendations because of the existence of disincentives [6]. Therefore, during the process of establishing guidelines, emphasis should be placed on the power and the feasibility of such guidelines to influence daily practice, that means attention must be payed to the implementation strategies. In this respect medical societies can play an important role.

In this article the experiences in The Netherlands, where professional societies play an important role in the procedure of consensus guidelines development, are described and the various interventions which have been undertaken to promote implementation are mentioned. Furthermore, these experiences are compared with new ideas in the U.S.A. regarding criteria setting.

\section{Determinants of the effectiveness of guidelines}

The most important condition guidelines must meet is that they are based on all scientific evidence that exists. However, it is known that scientific proof 
about the effectiveness is present for only 20 percent of all medical interventions [7]. Therefore clinical experience and opinion are also important in establishing guidelines. Apart from this basis on which guidelines are built, there are other determinants that will define the effectiveness of guidelines to change clinical behaviour. Following the process of development there are a number of factors to consider:

- the source of the guidelines: what is the authority of the organisation or group which has formulated the guidelines;

- the target of guidelines: the current interest in the topic and the number of patients concerned for which they were established [8];

- the text of the guidelines: guidelines must not be scholarly or discussive, rather didactive [9]. They have to be specific, narrow and restrictive [10];

- the diffusion of the guidelines: the way the guidelines reach the physician;

- the environment: all factors which influence the physician in his decision-making process, such as the availability of facilities, the method of reimbursement, his colleagues and the patient and his family.

To develop guidelines which are to influence the daily practice of physicians in the desired direction, these factors have to be taken into account.

\section{The Dutch experience with consensus guidelines}

There are several methods for developing guidelines, such as the Delphitechnique, nominal group process and consensus mectings. In The Netherlands, the National Organization for Quality Assurance in Hospitals (CBO) has chosen the method of consensus development conferences. This programme was started in 1982 to formulate explicit criteria for good medical care on a national level on controversial issues that could not be solved at the local hospital level. These criteria were used in peer review by medical staffs. So these consensus guidelines can be called boundary rather than pathway and from the beginning emphasis was put on the implementation of the guidelines. For general practitioners a so-called standard policy programme was started in The Netherlands in 1989: this programme will not be discussed in this article.

The CBO consensus methodology is based on two group processes. First, the work of a preparatory group of experts from medical societies who formulate answers to tentative questions posed at the beginning of the process. Second, the actual consensus meeting which is attended by health care providers interested in the specific topic and where all of the interested parties can comment on the consensus draft. Details of the consensus programme are described elsewhere [11-13].

The role of professional medical societies is substantial. The choice of topic is approved by the scientific council of the $\mathrm{CBO}$ in which all the official recognized medical specialties are represented. Often the topic is proposed by the medical societies themselves. The experts in the preparatory group are delegated by their societies. Furthermore, the meeting is organised in cooperation with the medical societies involved. In this way the authority of the source of the guidelines is 
guaranteed. Also the current interest in the topic and the relevance of the guidelines for daily practice seems to be ascertained.

The text of the guidelines is sent to all participants of the conference and to all hospitals. A summary is published in The Netherlands Journal of Medicine. However, not all guidelines are sufficiently specific and many are not described in detail [13]. Some of the consensus texts are also published in English-language journals.

During a study to investigate the effect of the consensus development program on physician behaviour in daily practice, the impact of four conferences have been measured: blood transfusion policy in hospitals, melanoma of the skin, prevention of bedsores and diagnosis of deep venous thrombosis [13]. Although the physicians were acquainted with the consensus statements and they have used them in setting up local protocols and conducting peer review studies, the compliance increased only up to a certain point $[13,14]$.

To promote the implementation of consensus guidelines three different interventions have been developed in the last few years by CBO.

Firstly, before the consensus conference is held current practice is measured. The results of this 'zero-measurement' can be used for various purposes:

to investigate how large the variation in practice is, as a reason for holding a conference on this topic;

for comparison with data after the conference to measure the effect on medical practice;

more important for the implementation: to show the large variation in practice to the health care providers as one of the attempts to motivate them to change their clinical behaviour.

As an example, the figure shows the results of a study on the use of serum protein measurements in clinical chemical laborates for the development of guidelines on the topic of management of patients with abnormal immunoglobulins. In all types

PROTEINELECTROPHORESIS

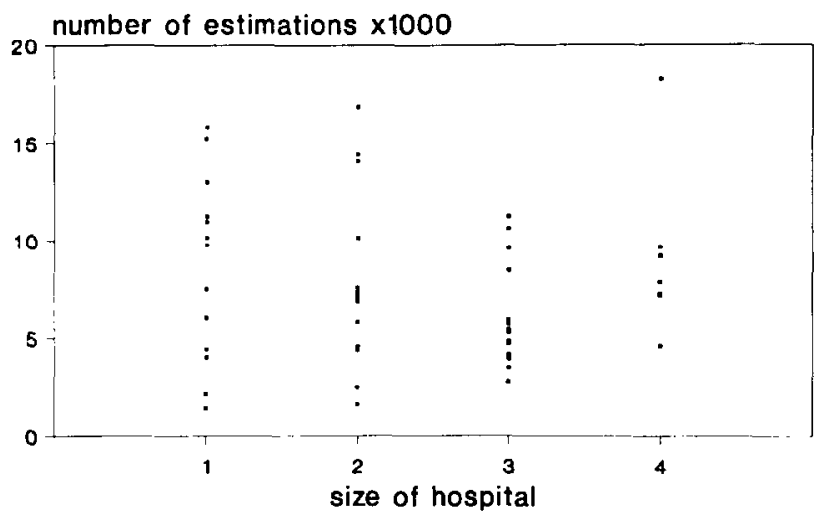

Fig. 1. Number of serum protein measurement per 1000 beds in scute care hoepltels in the Netherlands in 1987, in four differed sizes of hospitals. 1, 240-432 beds; 2, 433-600 beds; 3, 606-1360 beds; and 4, univeraity hospitals. Source: Dinkelaer of al. [15]. 
of hospital size there is a great variation in the number of estimations [15].

Secondly, the draft consensus statements are presented to a number of clinicians to ask their opinions and to check in advance whether there will be thresholds by following the guidelines in practice. By knowing these thresholds and analyzing the problems and the reasons for impediments, more realistic and feasible guidelines, which, however may be less scientific to some extent, can be formulated. Alternatively, solutions for the anticipated low compliance can be found. In this way incentives for use can be applied or disincentives for low compliance can be removed. During the preparation of a consensus development conference on prevention of hospital-acquired infections, an investigation was held on the opinions of physicians and nurses about handwashing and disinfection with soap and water after contact with a patient [16]. The most frequently stated reasons why handwashing was not always or even, hardly ever carried out in the proper way, were: "drying up of the skin; irritation of the skin; I often forget it (nurses) and I never see infection complications, even if I don't wash my hands while working (physicians)."

So to make feasible guidelines, the emphasis was placed, among other things on alcohol instead of soap washing. Furthermore, based on the results of the inquiry some recommendations for implementation have been made.

Thirdly, if appropriate, patient organisations are involved in consensus development. These organisations not only contribute to specific elements of some guidelines, but can also promote the dissemination of the guidelines to their members and the implementation of the recommendations through the contacts between members and physicians. For the consensus development conferences on follow-up of colon polyps, the complete text has been used for writing a patient information set by the patient organisation concerned, called "Liver and Gut Foundation". This set was sent to all hospitals where they have been placed in outpatient waiting rooms. Furthermore, on the basis of such guidelines these organisations can convince their members not to have too high expectations of the possibilities of health care provision, thus preventing overdiagnosis and overtreatment, if appropiate.

Although the effects of these interventions have not been studied in a systematic way, it seems obvious that they will all contribute towards better compliance of guidelines by physicians.

Besides the contribution to consensus development conferences, various scientific societies have established guidelines of their own. Formulating guidelines is usually assigned to the associations of subspecialists. In the table some examples of officially accepted guidelines in the large societies of officially recognized medical specialists are mentioned [17].

The contribution to guideline development is only one of the activities of the medical societies to quality improvement and quality assurance in The Netherlands. Most of the societies have a committee for quality improvement. Apart from formulating guidelines, visitation of non-teaching hospitals or departments by colleagues, evaluation of medical treatment and postgraduate training are also seen as methods for quality improvement by medical societies [15]. These activities can, in turn, promote the compliance of their members with guidelines. 
Table 1

Examples of offlcially accepted guidelines developed by scientific socioties in The Netherlands

\begin{tabular}{ll}
\hline Report: & "Quality control and standardization of allergen-containing extracts", published by \\
Reports: & The Netherlands Society of Allergology (Medisch Contact, 43 (1988) 1575-1576). \\
"Society views on anaethesiological practice" and "Society views on regional & anaesthesia"; Netherlands Society of Anaesthesiology. \\
Report: & "Use of omission of life-prolonging measures in neonatology"; Netherlands Society \\
of Paediatrics.
\end{tabular}

Guidelines for vitamin K treatment of infants; Netherlands Society of Paediatrics.

Guidelines for sclerosing of varices; Netherlands Society of Dermatology and Venereology.

Guidelines for quality control in health care laboratories, issued by the Coordinating

Committee for the Promotion of Quality Control in laboratory procedures in the field of health

care.

Guidelines on measurement bacterial resistance; Netherlands Society of Laboratory Physicians.

Guidelines for lower-leg amputation; Netherlands Society of Physicians in Rehabilitation and

Physical Medicine.

Guidelines for delimiting kerratomy; Netherlands Ophthalmological Society.

Guidelines for the preparation of cytostatic agents and for "Good Manufacturing Practice";

Netherlands Society of Hospital Pharmacists.

Source: Casparie et al. [17].

\section{New developments in the U.S.A.}

In the last few years interest in practice guidelines has spread rapidly throughout the health care system in the U.S.A. [1]. Many types of organisation are involved in guideline development, such as the federal government, insurance companies, health maintenance organisations, agencies, hospital associations, but also specialty societies and other physician organisations.

National medical specialty societies have been issuing practice guidelines for many years in the U.S.A.. Howcver, the involvement in this process has expanded in recent years. In 1990, at least 26 physician organisations had developed more than 700 practice guidelines and ten additional organisations had initiated plans to develop such guidelines [18].

Moreover, in the last few years the government has begun to develop and enforce practicc guidelincs. The Agency for Health Care Policy and Research (AHCPR) from the Department of Health and Human Services, established in January 1990, is responsible for facilitating the development, review and updating of relevant clinical guidelines to assist practitioners in the prevention diagnosis, treatment and management of clinical conditions [19]. In the development procedure, panels of qualified experts and health carc consumers are being used. The guidelines will be disseminated to practitioners, payers and reviewers. This approach places the government in the role of promoting the development and dissemination of practice guidelines on how physicians should evaluate and manage medical conditions.

Furthermore, insurers develop their own guidelines internally, sometimes in cooperation with physician organisations to enhance clinical input into their guidelines [1]. These guidelines are used as a basis for making claim decisions, utilisation assessments and selecting health care providers for insurance schemes.

In most publications in the U.S.A. emphasis is placed on the necessity for physician organisations to establish their own guidelines or to involve physicians in the 
development process. First, they have the expertise and credibility to develop practice guidelines that are both clinically reliable and acceptable to other physicians [19]. With regard to changing physician behaviour the participation of physician organisations is a necessary prerequisite in this view. Second, the medical profession has the responsibility to develop their own guidelines in a comprehensive and systematic way, otherwise other parties will develop their own guidelines, perhaps at the expense of the goal of quality of care.

However, there had been and there still is resistance from physicians to establish written guidelines, mainly because they are afraid they will be used against physicians in malpractice cases. However, the American Society for Anesthesiologists has recently developed standards and recommendations by which a decrease in premium costs for insurance could be brought in [20]. Furthermore, there has been no major case in which a written standard exclusively developed for risk management purposes was used as pivotal evidence in a malpractice trial [21].

Audet and co-workers have interviewed eight prominent organisations (three medical societies, two health care organisations, two insurers and one private benefits management company) about their approaches to guideline development [3]. Guidelines were being promoted as a means to improve the effectiveness of the health care system. They were able to discern three different methods: the experts who base their findings on available literature; a group consensus process; and a highly structured combination of the first two methods. The conclusion was that in all these methods more emphasis should be placed on implementation strategies. In general, much interest is placed on the scientific basis of the guidelines. They recommend that attention should be paid to the scientific evaluation of the effectiveness in a real clinical setting, such as on functional status, patient satisfaction and clinical outcome $[3,22]$.

In various articles there are reports of efforts to promote implementation of guidelines, but the approaches differ. Comparable with the second strategy in The Netherlands, the developing process in the American Academy of Ophthalmology starts with circulation of a model set of preferred practice guidelines to its Council, a broadly representative body [23]. Within the Harvard Community Health Plan a variety of complementary strategies is applied to promote implementation, such as reminder systems and administrative changes, such as changes in laboratory test order forms [22]. In connection with the third of the Dutch strategies mentioned, the involvement of patient organisations, it is particulary interesting to note the initiative of the American College of Physicians to write a patient education newsletter that will summarise their guidelines [24]. So far no results have been published of a systematic evaluation of the impact of the guidelines. It is known that the effects of recommendation from consensus development conferences of the National Institutes of Health are minimal [25].

\section{Discussion}

In comparing the approach of the development of guidelines between the U.S.A. 
and The Netherlands, apart from the similarities, there are some differences. In The Netherlands, guidelines development is anchored in peer review activities. So from the beginning, attention was paid to the implementation phase and the feasibility in practice rather than on scientific validity. Therefore in the procedure of guidelines development, the practising physician played an important role, especially at the consensus meeting. Although the medical societies organise the meeting and delegate their experts, it is the physicians in the frontline who have to apply the guidelines [1]. But it became clear that even with the active involvement of medical societies and some of their members, other mentioned interventions must be taken to promote implementation, such as zero-measurement, tracing thresholds and contributions from patient organisations.

In the U.S.A. the issue of scientific evidence as the starting point seems to be more important. This is also evident from the above-mentioned necessity of measuring the effectiveness of the guidelines on health status and so on. In The Netherlands the view is taken that the formulated guidelines emcompass all scientific evidence and clinical expertise available, so there is really no need to prove they are right, or to do scientific validation studies. Of course, the level of certainty regarding the scientific evidence should be indicated.

In the U.S.A., physician associations are also incorporated into the development of guidelines. In The Netherlands, no other organisations exist that issue practical guidelines. From the Dutch experience it can be concluded that far greater involvement of the medical societies is necessary if guidelines are to be followed by the practising physicians. Under the auspices of the societies, thresholds can be traced by asking practising physicians and by testing draft guidelines in their practice. Ideally, guidelines should also contain recommendations for implementation. Furthermore, medical societies have a responsibility for quality improvement and quality assurance and they should have a systematic and structured approach to promote quality of care. In this connection, guidelines development is only one of the activities.

In conclusion: the primary goal of guidelines is to improve the quality of care by changing the daily practice of physicians in the desired direction. Therefore, besides the scientific basis of guidelines, emphasis should be placed on the implementation of these guidelines. In this respect, medical societies and their members play a crucial role whether the guidelines will be effective or not in shaping clinical practice.

\section{References}

1 Woolf, S.H., Practical Guidelines: A new Reality in Medicine, Archives of Intemal Medicine 150, (1990) 1811-1818.

2 Eddy, D.M., Resolving Conflicts in Practice Policies, Journal of the American Medical Association 264, (1990) 389-391.

3 Audet, A.M., Greenfield, S. and Field, M., Medical Practice Guidelines: Current Activities and Future Directions, Annals of Internal Medicine, 113 (1990) 709-714.

4 McGuire, L.B.A. and Hong, A., Run for a Short Jump: Understanding Clinical Guidelines, Annals of Internal Medicine, 113 (1990) 705-708. 
5 Eddy, D.M., Practice Policies - What Are They? Journal of the American Medical Association, 264 (1990) $877-880$.

6 Lomas, J., Anderson, G.M., Dominick-Pierre, K., et al., Do practice guidelines guide practice? The effect of a consensus statement on the practice of physicians. New England Journal of Medicine, 321 (1989) 1306-1311.

7 Eddy, D.M. and Billings, J., The Quality of Medical Evidence: Implications for Quality of Care, Health Affairs, Spring 1988: 19-32.

8 Mullan, F. and Itzhak, J., The town meeting for technology. The maturation of consensus conferences, Journal of the American Medical Association, 254 (1985) 1068-1072.

9 Kahan, J., Kanouse, D. and Winkler, J., Stylistic variations in National Institutes of Health consensus statements, 1979-1983, International Joumal of Technology Assessment in Health Care, 4 (1988) 289-304.

10 Leape, L.L., Practice Guidelines and Standards: An Overview, Quality Review Bulletin, February 1990: 42-48.

11 Casparie, A.F., Van Everdingen, J.J.E., Consensus Development Conferences in The Netherlands, International Journal of Technology Assessment in Health Care, 1 (1985) 905-912.

12 Klazinga, N.S., Casparie, A.F., Van Everdingen, J.J.E., Contribution of medical decision-making to consensus developement conferences, Health Policy, 8 (1987) 339-346.

13 Van Everdingen, J.J.E., Consensus ontwikkeling in de geneeskunde (Consensus development in medicine), in Dutch with a summary in English, Thesis Amsterdam, 1988.

14 Van Everdingen, J.J.E., Rampen, F.H.J., Ruiter, D.J. and Casparie, A.F., Evaluation of consensus development conference on cutaneous melanoma in The Netherlands, British Journal of Dermatology, 123 (1990) 259-260.

15 Dinkelaar, R.B.D., Beunis, M.H., Oosterhuis, W.P. and Van Everdingen, J.J.E., CBO-enquête paraproteinemie, Nederlands Tijdschrift voor Klinische Chemie (submitted) (Dutch) (CBO-enquête paraproteincamia).

16 Grol, R., Kistemaker, W. and Hanrahan-Cahuzak, M., Invoering van consensus richtlijnen. Preventie van ziekenhuisinfecties (Dutch), (Introduction of consensus guidelines. Prevention of hospital acquired infections), Medisch Contact, 46 (1990) 517-521.

17 Casparie, A.F., Van Everdingen, J.J.E. and Touw, P.P.J., Kwaliteitsbevordering en kwaliteitsbewaking: een taak van de wetenschappelijke verenigingen? (Dutch) (Quality improvement and quality assurance: a task of the scientific medical societies?) Medisch Contact, 45 (1989) 1478-1481.

18 Kelly, and.T., Swartwout, J.E., Development of Practice Parameters by Physician Organisations, Quality Review Bulletin 1990, February, 54-57.

19 AHCPR program note, Agency for Health Care Policy and Research, Rockville U.S.A., August 1990.

20 Pierce, E.C., The Development of Anesthesia Guidelines and Standands Quality Review Bulletin, February 1990, 61-64.

21 Holzer, J.F., The Advent of Clinical Standards to Professional Liability. Quality Review Bulletin 1990, February 71-79.

22 Gottlieb, L.K., Margolis, C.Z. and Schoenbaum, S.C., Clinical Practice Guidelines at an HMO Development and Implementation in a Quality Improvement Model. Quality Review Bulletin 1990, February, 80-86.

23 Sommer, A., Weiner, J.P. and Gamble, L., Developing Specialty wide Standards of Practice: The Experience of Ophthalmology, Quality Review Bulletin 1990, February, 65-70.

24 White, L.J. and Ball, J.R., Integrating Practice Guidelines with Financial Incentives, Quality Review Bulletin 1990, February, 50-53.

25 Kosecoff, J., Kanousse, D.E., Rogers, W.H., McCloskey, L., Winslow, C.M. and Brook, R.H., Effects of the National Institutes of Health Consensus Development Program on Physician Practice, Journal of the American Medical Association, 258 (1987) 2708-2713. 